\title{
Academic medicinal chemistry: no country for young men (or women)?
}

\author{
"...harnessing chemistry in the pursuit of drug discovery has \\ deep historical roots in academia."
}

Keywords: medicinal chemistry $\bullet$ penicillins $\bullet$ rational drug design $\bullet$ teaching Med Chem
- tuberculosis

My brother Barry died in 1948 from encephalitis after desperate attempts to spare his life by administering a May $\&$ Baker drug, probably M\&B 693 (sulfapyridine), which had earlier saved Winston Churchill from bacterial pneumonia. Our paternal grandmother Annie Florence Golding had died from tuberculosis in 1924 aged 25, after being consigned without treatment, none being then possible, to the Victorian workhouse in Willesborough, Kent - our father was thus orphaned aged 2. These events, the like of which many of us may uncover within our ancestry, framed my education and led to a career in chemistry and medicinal chemistry, where my ambition was and is to create molecules that alleviate human suffering from disease. Alongside my research, I have pioneered teaching programs in medicinal chemistry, which were initially limited in scope, but at Newcastle University grew into fully fledged undergraduate degree courses (BSc and $\mathrm{MChem}$ ) in medicinal chemistry and a masters course (MSc) in drug chemistry.

The rational design of new drugs is nothing new and harnessing chemistry in the pursuit of drug discovery has deep historical roots in academia. An institute was founded in Dorpat, Estonia in 1847, where the pharmacologist Richard Buchheim pioneered the study of the mechanism of action of drugs [1]. His successor Oswald Schmiedeberg was a pharmacologist and natural products chemist, who built on research dating back to 1806 , when the pharmacist Friedrich Sertürner isolated pure crystalline morphine from poppies. By 1850, numerous alkaloids, including some of the most poisonous (e.g., hyoscyamine and strychnine), had been crystallized. Since then, the chemical literature is replete with examples of biologically active compounds from natural sources and an industry to exploit these mainly academic discoveries developed from the mid-19th century. As structural and synthetic chemistry advanced in the second half of the 19th century, so synthetic drugs appeared, initially sedatives (e.g., diethylbarbituric acid prepared by Emil Fischer in 1902), anaesthetics (e.g., Procaine synthesized by Alfred Einhorn in 1905) and antiparasitic drugs (e.g., Salvarsan developed by Paul Ehrlich in the period up to 1909). Ehrlich's optimization strategy ("preparing homologues and derivatives .... from substances having a certain effectiveness") still guides us today [2].

The first half of the 20th century was a period of consolidation severely interrupted by two world wars, which abrogated Germany's scientific prowess that had been so well exemplified before 1914. In the rather barren period up to 1945 , notable findings were the antibacterial sulfonamide named Prontosil (1935, discovered by Gerhard Domagk at I.G. Farben, Germany), which preceded M \& B's sulfapyridine and the first antibiotics (penicillin $\mathrm{G}$ and streptomycin). But soon, inspirational work by the 'superpenicillin' team of Batchelor, Doyle, Naylor and Rolinson in the 1950s at the UK company Beechams (founded in the 1840s) led to semisynthetic penicillins with much improved antibacterial profiles [3]. At that time few chemistry undergraduates were taught this achievement and

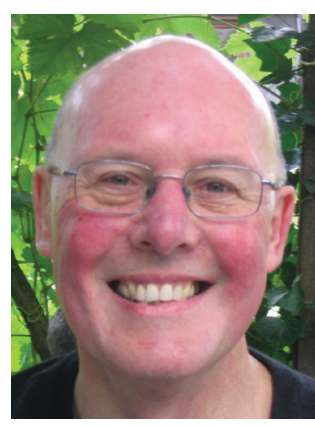

Bernard T Golding School of Chemistry, Bedson Building, Newcastle University, Newcastle upon Tyne, NE1 7RU, UK bernard.golding@ncl.ac.uk 
an insidious separation between academia and the pharmaceutical industry evolved. A certain 'big pharma' arrogance was manifest with claims that chemistry graduates need not be taught medicinal chemistry as they would learn on the job all that would be required. Rather, 'synthesis synthesis synthesis' was essential and would then be applied in pharma under the guidance of a 'med chem guru.' This reactionary attitude ignored the downward spiral of applications to study chemistry in the 1970s and 80s, which inevitably impacted on the industry. And for a long time, advances in enzymology, and molecular and structural biology, were alien to most chemistry courses, while the latest organometallic reaction became the trendy topic. Today, no chemistry student of any persuasion should graduate without knowledge of protein and DNA structure, alongside all that palladium-catalyzed stuff.

Faced with the static nature of chemistry applications in the 1980s, I initiated the chemistry with medicinal chemistry course at Newcastle in 1989. The opinions of pharma experts were sought, but although these were mostly negative we plowed on regardless, only noting their plea that synthetic organic chemistry must not be sacrificed or downplayed. This initiative was not only for reasons outlined above, but also to tap into an unmet need for a course suitable for students, who like the young me, wanted to learn chemistry as a platform for drug discovery. These students were being lost to medicine, pharmacy or pharmacology. Now it is difficult to find a chemistry department in the UK that does not offer a course in medicinal chemistry, many others having latched on to our solution to the student numbers dilemma. The Newcastle chemistry course has always attracted a sizeable cohort of medicinal chemistry students: about one quarter of the total annual intake, which is currently approximately 130 .

Chemicals tend to get a bad press because of the public's perception that they may be associated with dangers to the environment and human health. The many benefits of chemicals, for example as drugs, which may not even be recognized as chemicals, are overlooked. As indicated above, many drugs have emerged from the pharmaceutical industry, often derived from academic research, but there has been a decline in the number of new products, partly due to the ever greater emphasis on proof of safety. It has been argued that future drug development will benefit from chemists trained in toxicology [4]. Such individuals will help to avoid the development of compounds that ultimately will fail as drugs because of toxicological issues. Likewise, the prevention of human exposures to chemical toxicities requires a better understanding of the toxicology of all kinds of chemicals. Thus, an essential component of the Newcastle med chem course is drug metabolism and toxicology, which provides an education in some of the key issues in areas relevant to the pharmaceuti$\mathrm{cal}$ and chemical industries. While teaching medicinal chemistry, I have come to realize that the loftiness of UK pharma referred above was actually quite justified by virtue of its continuous stream of new medicines, which have markedly contributed to ever-increasing human life expectancy [5]. Our med chem undergraduates know this - we tell them the brilliant story of the rational development of the antimigraine drug sumitriptan by a team of chemists and pharmacologists at Glaxo [6,7], and much more.

\section{"...let us go forward, academia and pharma in concert confronting the labyrinth of remaining challenges..."}

Of critical importance is the requirement that medicinal chemistry is taught by research-active medicinal chemists, which has been the case from the outset at Newcastle, but not everywhere. Graduates from our courses segued to $\mathrm{PhD}$ training or to careers in pharma, which has relaxed its antagonism to academic med chem courses. Many of the graduates joined the drug therapeutics group within the Northern Institute for Cancer Research at Newcastle and contributed to the development of potent inhibitors of targets implicated in the molecular pathology of cancer. One such project, which was a collaboration between Roger Griffin and myself with colleagues in the Newcastle Medical School and Agouron Pharmaceuticals (San Diego), led to Rucaparib, the first-in-class clinical candidate targeting the DNA repair enzyme poly-ADPribose polymerase-1 (PARP-1) [8]. Now every big pharma on the planet seems to have a PARP program with some of their inhibitors looking like Newcastle prototypes for rucaparib [9]. But let us focus on the patient! Rucaparib and competing PARP inhibitors have already improved the lives of many patients in clinical trials [10]. So let us go forward, academia and pharma in concert confronting the labyrinth of remaining challenges, not forgetting tuberculosis, which still kills over 1 million people per annum [1].

\section{Acknowledgement}

This editorial is dedicated to RJ Griffin (1955-2014), a brilliant academic medicinal chemist and key member of the Newcastle team that contributed to the development of the anticancer drug Rucaparib.

\section{Financial \& competing interests disclosure}

The author has no relevant affiliations or financial involvement with any organization or entity with a financial interest in or financial conflict with the subject matter or materials discussed in the manuscript. This includes employment, consultancies, 
honoraria, stock ownership or options, expert testimony, grants or patents received or pending, or royalties.

\section{References}

1 Scheindlin S. Our man in Dorpat: Richard Buchheim and the birth of pharmacology. Mol. Interv. 10(6), 331-335 (2010).

2 Hubbard LS, Huber GL, Menzi K. The Story of the Chemical Industry in Basle. Urs Graf Publishers, Olten and Lausanne, Switzerland (1959).

3 Rolinson GN. Forty years of $\beta$-lactam research. J. Antimicrob. Chemother. 41(6), 589-603 (1998).

4 Gant TW. Skills and training for the $21^{\text {st }}$ century chemical toxicologist. Chem. Res. Toxicol. 24(7), 985-987 (2011).

5 Alex AA, Storer RI. Drugs and their structural motifs. In: RSC Drug Discovery Series No. 1. Smith DA (Ed.). Royal Society of Chemistry, Cambridge, UK, 1-60 (2010).

6 North PC, Oxford AW, Fenuik W, Humphrey PPA, Connor HE. Migraine therapy - from serotonin to sumatriptan.
No writing assistance was utilized in the production of this manuscript.

In: Medicinal Chemistry Principles and Practice. King FD (Ed.). Royal Society of Chemistry, Cambridge, UK, 265-277 (1994).

7 Humphrey PPA. The discovery of a new drug class for the acute treatment of migraine. Headache 47(Suppl. 1), S10-S19 (2007).

8 White AW, Griffin RJ, Golding BT et al. Synthesis and biological properties of benzimidazole inhibitors of the DNA repair enzyme poly(ADP-ribose) polymerase. J. Med. Chem. 43(22), 4084-4097 (2000).

9 Ferraris DV. Evolution of poly(ADP-ribose) polymerase-1 (PARP-1) inhibitors. From concept to clinic. J. Med. Chem. 53(12), 4561-4584 (2010).

10 Plummer R. Poly(ADP-ribose) polymerase (PARP) inhibitors: from bench to bedside. Clin. Oncol. 26(5), 250-256 (2014).

11 Bourzac K. Beating the big three. Nature 507(7490), S4-S7 (2014). 